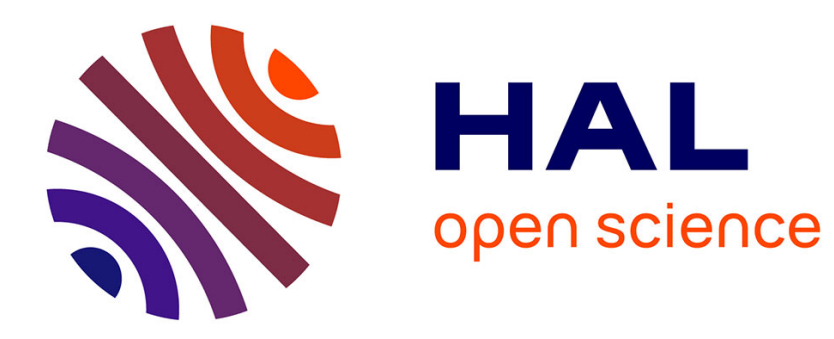

\title{
Dislocation Mechanisms for Shock-Induced Hot Spots
}

R. Armstrong

\section{- To cite this version:}

R. Armstrong. Dislocation Mechanisms for Shock-Induced Hot Spots. Journal de Physique IV Proceedings, 1995, 05 (C4), pp.C4-89-C4-102. 10.1051/jp4:1995407 . jpa-00253706

\section{HAL Id: jpa-00253706 https://hal.science/jpa-00253706}

Submitted on 1 Jan 1995

HAL is a multi-disciplinary open access archive for the deposit and dissemination of scientific research documents, whether they are published or not. The documents may come from teaching and research institutions in France or abroad, or from public or private research centers.
L'archive ouverte pluridisciplinaire HAL, est destinée au dépôt et à la diffusion de documents scientifiques de niveau recherche, publiés ou non, émanant des établissements d'enseignement et de recherche français ou étrangers, des laboratoires publics ou privés. 


\title{
Dislocation Mechanisms for Shock-Induced Hot Spots
}

\author{
R.W. Armstrong \\ Department of Mechanical Engineering, University of Maryland, College Park, MD 20742, U.S.A.
}

\begin{abstract}
Crystal dislocations provide the ultimate source of localized damage enhancement within solid materials. Vortices are the dislocation counterparts within liquids and gases. For energetic crystals, tubular holes might run along the pre-existent dislocation line lengths and act as shock-induced "in-situ" hot spots. Beyond this consideration, nearly invisible clouds of dislocations are possibly generated at point defects or point defect clusters by the shear stresses at a shock front. Multiple fine scale dislocation movements provide a mechanism for the shock to move to a hydrostatic stress state. Interatomic or intermolecular separations of the order of critical reaction coordinate distances are achievable during the unit dislocation displacements --. without change in material volume. Such nanoscale dislocation predictions connect with microscale experiments in a number of cases where larger scale "defect" considerations are involved. Dislocation pile-ups in slip band avalanches, often associated with cracking, account for very appreciable and localized heating that is deformation rate dependent. Complex dislocation slip band interactions occur within the plastic zones of macroscopic crack tips to control the fracture toughness properties of energetic and related materials.
\end{abstract}

\section{INTRODUCTION}

Individual dislocations in energetic crystals have special properties at nanoscale dimensions that relate both to microscopic and macroscopic aspects of detonation. In addition, shock loading produces a nanoscale dislocation network that, depending on the strength of the shock, will influence the generation of hot spots during the follow-on plastic deformation that occurs just behind the shock front. Thus, shock-induced hot spot development involves an added deformation feature that has to be considered when making comparisons with hot spot origins in drop-weight impact tests.

\subsection{Energetic crystal dislocations at nanoscale dimensions}

The large lattice parameters of energetic crystals lead to an elastic strain energy centered on the dislocation core position that is also relatively large, compared to the crystal surface energy, so that a tubular hole running along the dislocation line is preferred over the occurrence of severely strained molecules at the heart of the dislocation [1]. Figure 1 shows in (a) a unit cell for the orthorhombic crystal structure of cyclotrimethylene-trinitramine $(\mathrm{RDX})$ and in (b) a (002) plane view of a dislocation proposed to explain [100] direction slip on the (040) slip plane. The large size of molecules clearly puts them at out-of-place positions near to the dislocation origir. 

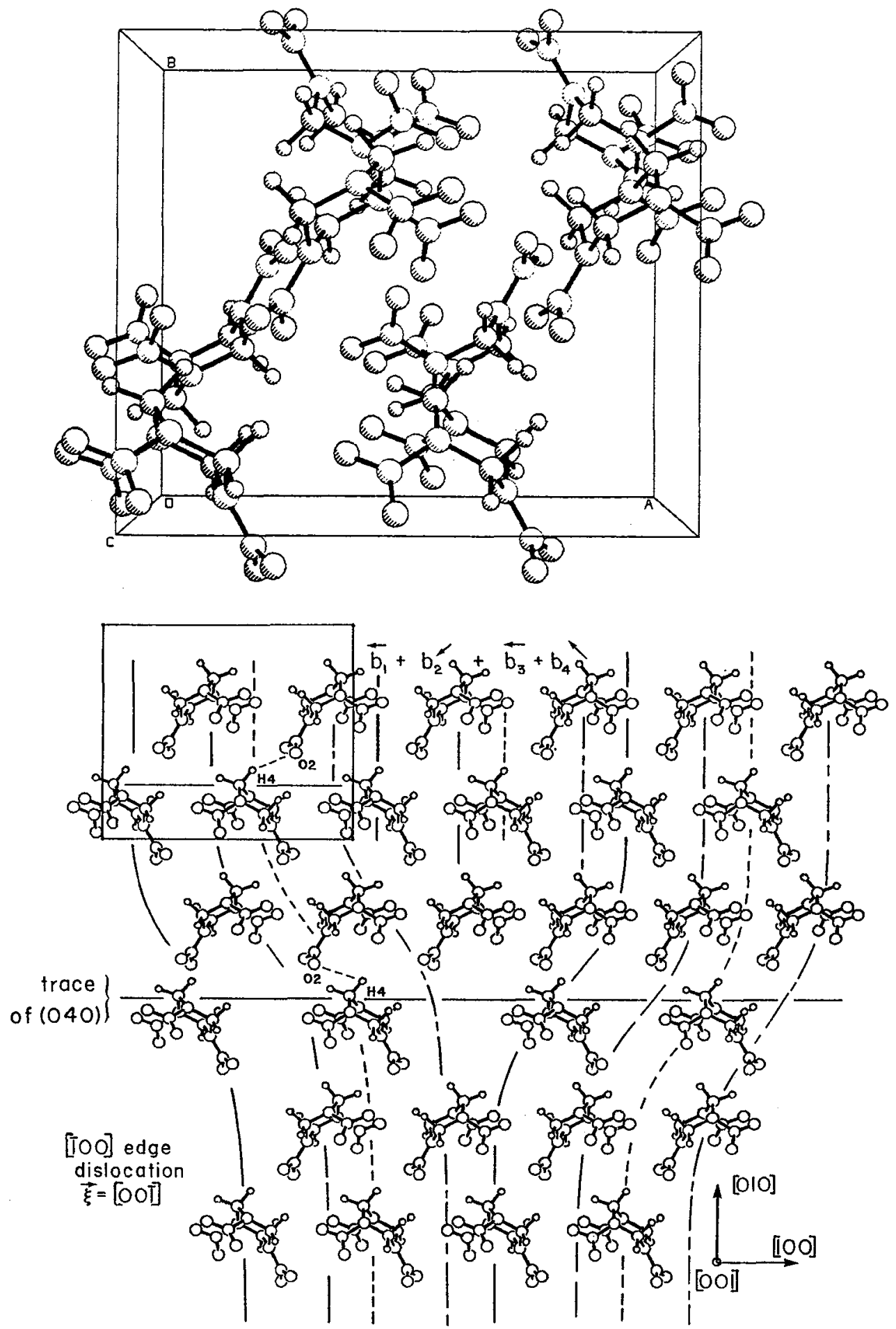

Figure 1a,b. RDX orthorhombic cell and [100](040) edge dislocation. 
The comparison of dislocation strain energy and surface energy is connected with an intrinsic ductility index of (surface energy divided by the product of shear modulus and dislocation Burgers vector) that is low for energetic materials [2,3]. Also, the rather dense packing of irregularly shaped molecules, for example in RDX, has been shown on an atomic model basis to obstruct the sequential shear displacements that would normally facilitate easy dislocation movement [4], thus explaining measurements of a pronounced resistance to plastic flow at microhardness indentations [5]. In a related important connection, the molecularly "hindered" shear of slip planes in pentaerythritol tetranitrate (PETN) crystals has been proposed to control their sensitivity to shock initiation of detonation $[6,7]$.

\subsection{Nanoscale shock structures}

The generation of a nanoscale dislocation structure at a propagating shock front was initially proposed in a pioneering study to explain measurements of shock hardening in metals [8]. The model was extended to give estimations of dislocation densities that would match post-shock strengthening measurements [9]. A more recent model involves the periodic generation of nanoscale dislocation loops by shear stresses at the shock front and the reaction of these loops to form a residual nanoscale dislocation dipole structure with resultant Burgers vectors parallel or antiparallel to the shock propagation direction [10]. The model has been related to the previous consideration of shock hardening measurements in metals [11] but, also, the model has been connected with molecular dynamics calculations performed to describe the generation of hot spots by shocks in energetic crystals [12].

\subsection{Drop-weight impact tests}

Hot spots and the initiation of chemical decomposition were associated with the occurrence of discontinuous load drops in transmitted pressure-time curves measured for drop-weight impact tests on RDX, PETN and related materials [13]. A microscopic explanation of the behavior was given in terms of the hot spots being generated when dislocation pile-up avalanches were released from blocked slip bands at obstacles [14]. On this model basis, the crystal size dependence of drop-height sensitivity measurements was predicted [15] and the mechanically-induced hot spot sizes were compared with direct thermal model calculations [16].

\section{DISLOCATION ATTRIBUTES IN ENERGETIC CRYSTALS}

The relatively weak molecular or hydrogen bonding of energetic crystal lattices leads to the possibility of numerous dislocations being formed within the lattice structures depending on thermal fluctuations or solute influences that occur during even the most careful crystal growth procedures. For example, a large variety of dislocation Burgers vectors and line vectors has been observed with the method of $\mathrm{x}$-ray diffraction topography applied to mapping dislocation distributions in carefully solution-grown crystals of RDX [17]. The ease with which dislocations might be formed in these materials, however, contrasts with the apparent contradiction that the dislocation strain energies are relatively large compared to the heat of fusion, because of the large Burgers vectors [18].

\subsection{Crystal growth observations}

A detailed description has been given of the relationship of dislocation Burgers vectors and line vectors to the characteristic internal growth sector microstructures and external polygonal crystal morphologies obtained with the growth-from-solution techniques normally employed for non-metallic crystals [19]. The dislocation lines generally run normal to the growth surface facet planes. Figure 2a,b shows an example of the growth morphology and sectioned internal growth sector microstructure obtained for an individual RDX crystal particle [20]. The resultant facet planes in Figure 2a and previous facet planes in Figure $2 b$ are identified from crystallographic calculations reported for RDX planes and directions [21].

Dislocation structures relating to external growth morphologies observed for RDX were reported previously in another $x$-ray diffraction topography study [22]. In Figure 2a, probable dislocation line emergence points are marked at A, B, C, and D. Other tabular crystal morphologies and a new growth 

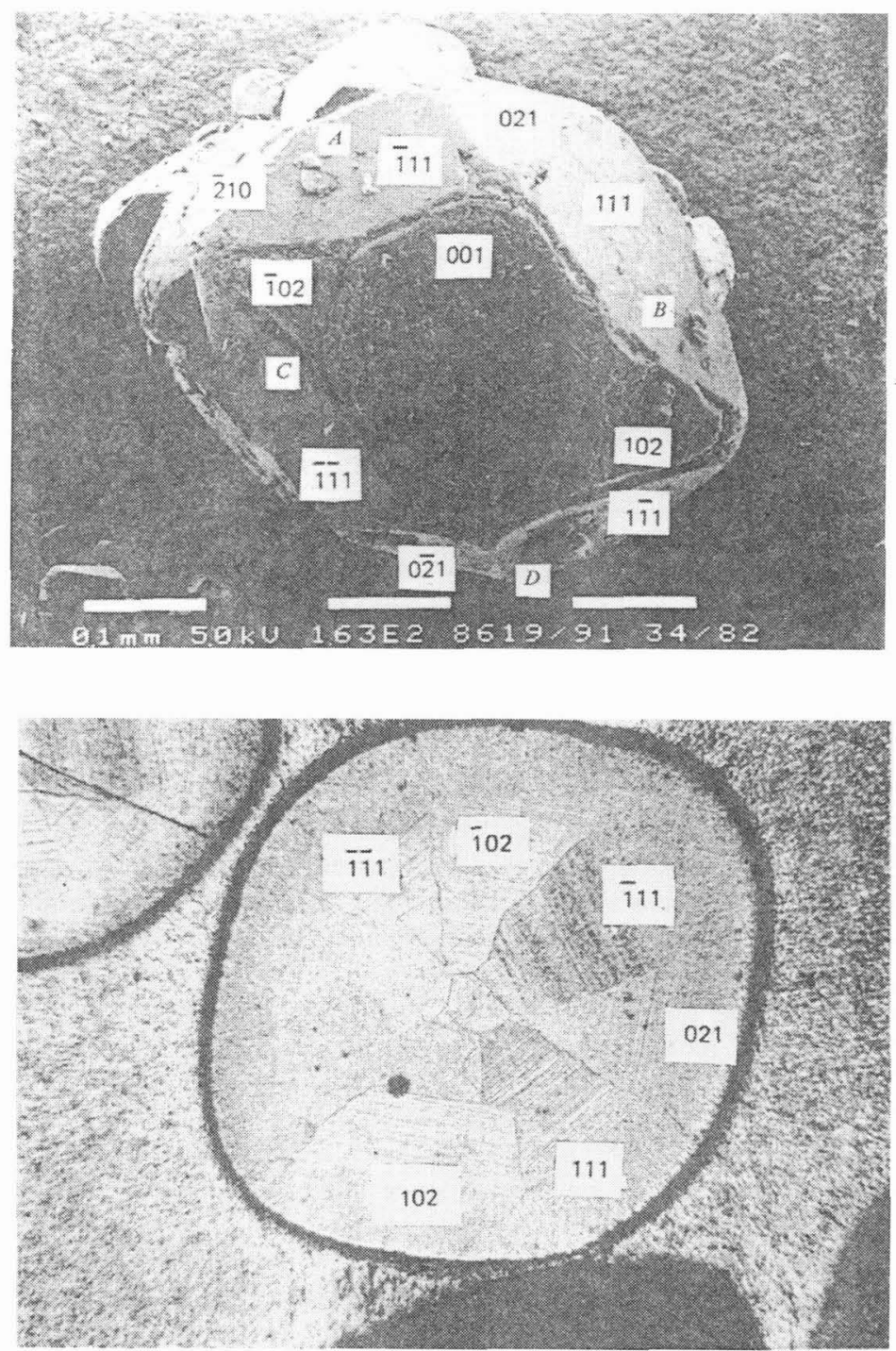

Figure 2a,b. RDX particle morphology and sectioned growth sectors.

morphology were identified for RDX in [21] and, consequently, other dislocation substructures would be included within the crystals. In this way, the variety of growth morphologies observed for RDX crystals provides evidence of the varying dislocation substructures that are contained within the crystals.

\subsection{Dislocation "immobility"}

The restricted extent of dislocation slip surrounding microhardness indentations in RDX [5, 23] led to the consideration that the interleaved nature of rather complex molecules in the relatively dense lattice structures of energetic materials provided the primary basis for a self-resistance to dislocation movement. On this basis, [100] direction slip in RDX on an (040) slip plane .rus proposed as an example of a relatively easy slip path to explain previously reported slip observations. Also, limited slip on (021) planes was identified at microhardness indentations [24]. 


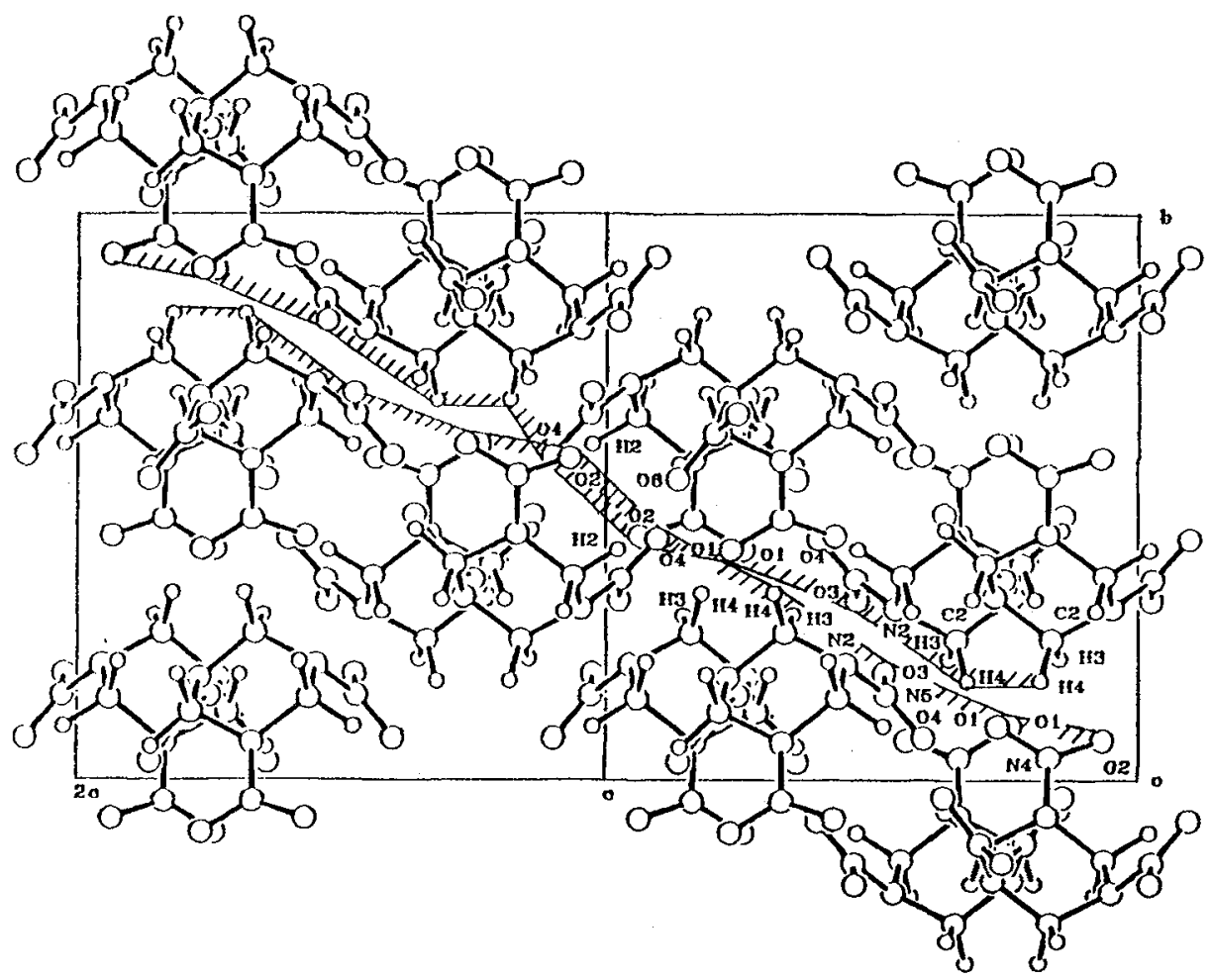

Figure 3. RDX molecule interactions for [100](02) slip.

Figure 3 shows a model of [100] slip on the (02) plane crossing two unit cells in RDX. At the vertical (001) plane junction of the cells, interactions are shown for two pairs of oxygen atoms in outcropping ONO groups between adjacent molecules. The particular interactions that are shown are those that would be involved in removing one oxygen atom in each case from adjacent ring extensions to form 1,3-dinitroso-5-nitro-1,3,5-triazacyclohexane. This compound was detected in drop-weight impact test specimens of RDX recovered from tests at near initiation drop-heights [25].
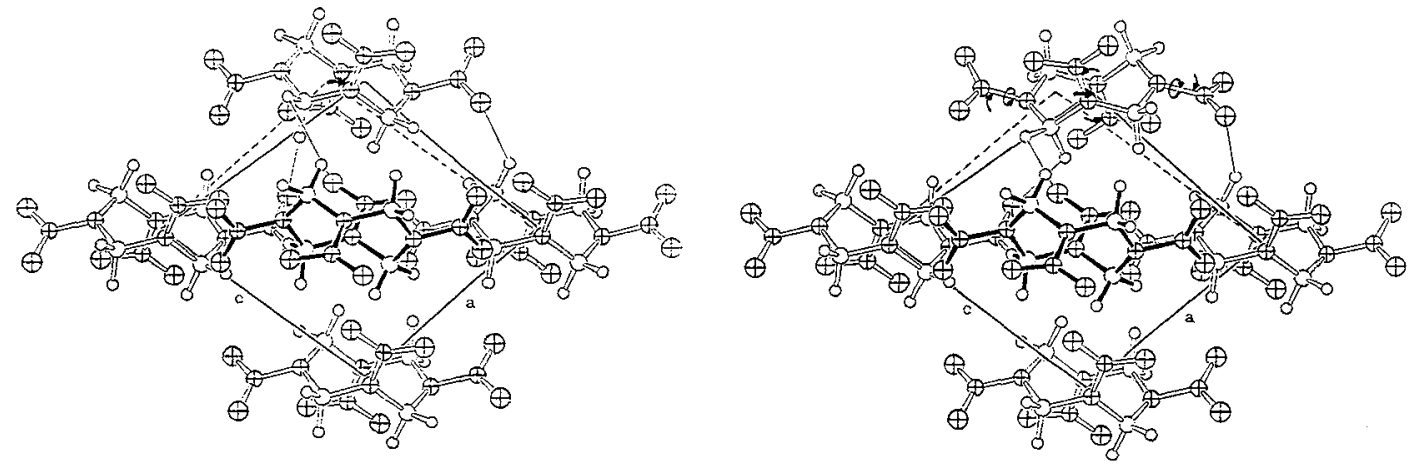

Figure 4. HMX molecule translations and rotations for (101)[10ī] Type II deformation twinning. 
An explanation of the difference between slip deformation being observed, though with difficulty, in RDX and deformation twinning being observed as a primary deformation mechanism in (harder) crystals of cyclotetramethylenetetranitramine ( $\mathrm{HMX}$ ) has been proposed to be rooted in the more flexible structure of the larger HMX molecule [26]. Figure 4 shows a possible mechanism for the $\{110\}$ type II deformation twinning structure that is proposed to occur in the monoclinic HMX crystal lattice. Molecular rotations are indicated to occur within the molecule in addition to the required translational displacements.

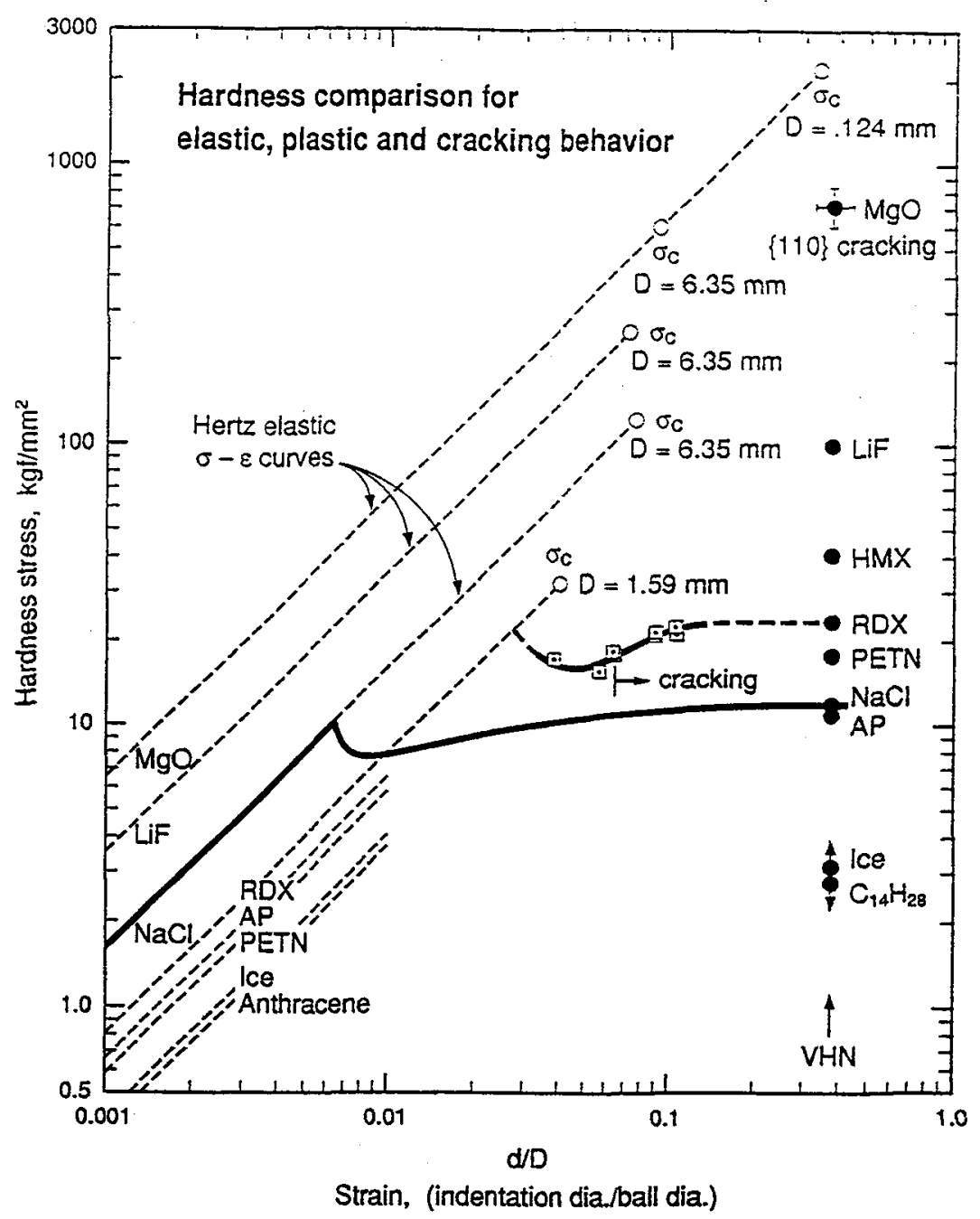

Figure 5. Elastic, plastic and cracking indentation hardnesses.

\subsection{Microhardness assessment}

The stresses for plastic flow and cracking of energetic crystals are able to be compared on the continuous indentation hardness basis that is shown in Figure 5. The hardness stress is given by the load divided by the projected area of the indentation and the hardness strain is specified as the ratio of contact diameter for a ball indenter divided by the ball diameter. The logarithmic scale for the indentation stress-strain behavior covers a substantial range in stress and strain values that are applicable for the initial (Hertzian) elastic loading response, the onset of progressive plastic flow, and a theoretical limiting elastic cracking condition [27]. 
The computed linear elastic loading responses of the different materials, indented in each case with a steel ball, are shown along the left edge of Figure 5, beginning at the lowest stress and strain values. For these lines, larger elastic stress values at any strain are indicative of larger elastic moduli, for example, for elastically stiff $\mathrm{MgO}$ as compared with elastically compliant anthracene crystals. The low elastic modulus of RDX is significantly less than that of $\mathrm{NaCl}$. A continuous ball indentation test result is shown for an $\mathrm{NaCl}$ crystal as the heavy curve leading from elastic loading behavior to plastic flow and eventually matching with a Vickers hardness measurement plotted at an equivalent hardness strain of 0.375 . By comparison, separate ball test results are shown for indentations put into an RDX crystal and including a theoretical hardness cracking stress shown on the elastic loading line for the $1.59 \mathrm{~mm}$. diameter ball employed in the measurements. The comparison with $\mathrm{NaCl}$ shows that $\mathrm{RDX}$ is more compliant but has a higher plastic flow strength, near to the theoretical limiting cracking stress. The comparison is in line with the dislocation structure considerations described in the preceding Sections and with an analysis of the limited intrinsic ductility to be expected for RDX [3].

\section{SHOCK DEFORMATIONS ON THE NANOSCALE}

Figure 6 shows the dislocation model that has been proposed to explain shock hardening of materials
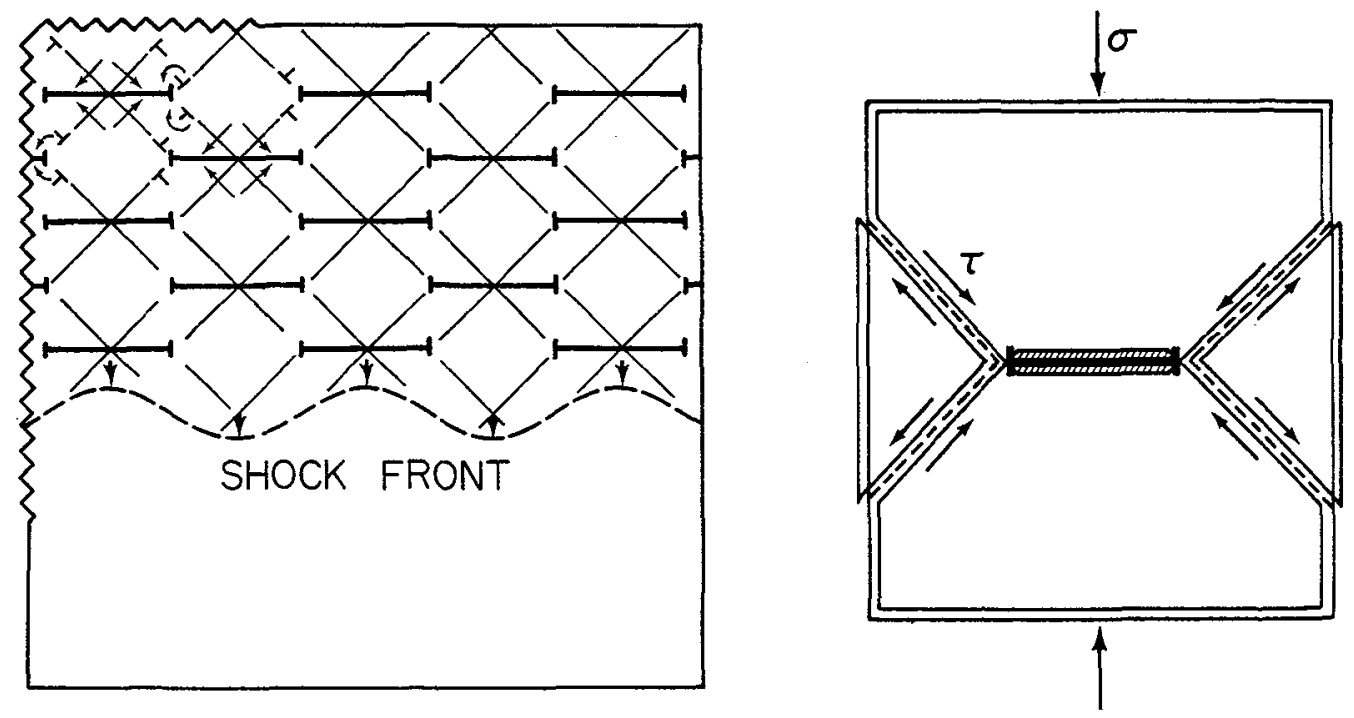

Figure 6. Nanoscale dislocation dipole model for shock damage.

and, in particular, has been proposed to be involved in shock-induced hot spot initiations of energetic materials [10]. For this ideal representation, the large strain induced at all points along the shock front is proposed to initiate numerous elemental shear zones. The sense of shear for the dislocation displacements is determined by the compressive stress. With lateral constraint, the dislocation displacements move the stress state towards a hydrostatic environment. The elemental crossed shears of the individual loops are distributed in a manner to give dislocation reactions at intertwined slip intersections so that a residual state of one-dimensional strain is achieved for the resultant dislocation structure. The proposed nanoscale structure appears to give a reasonable explanation of shock hardening observations [11]. 

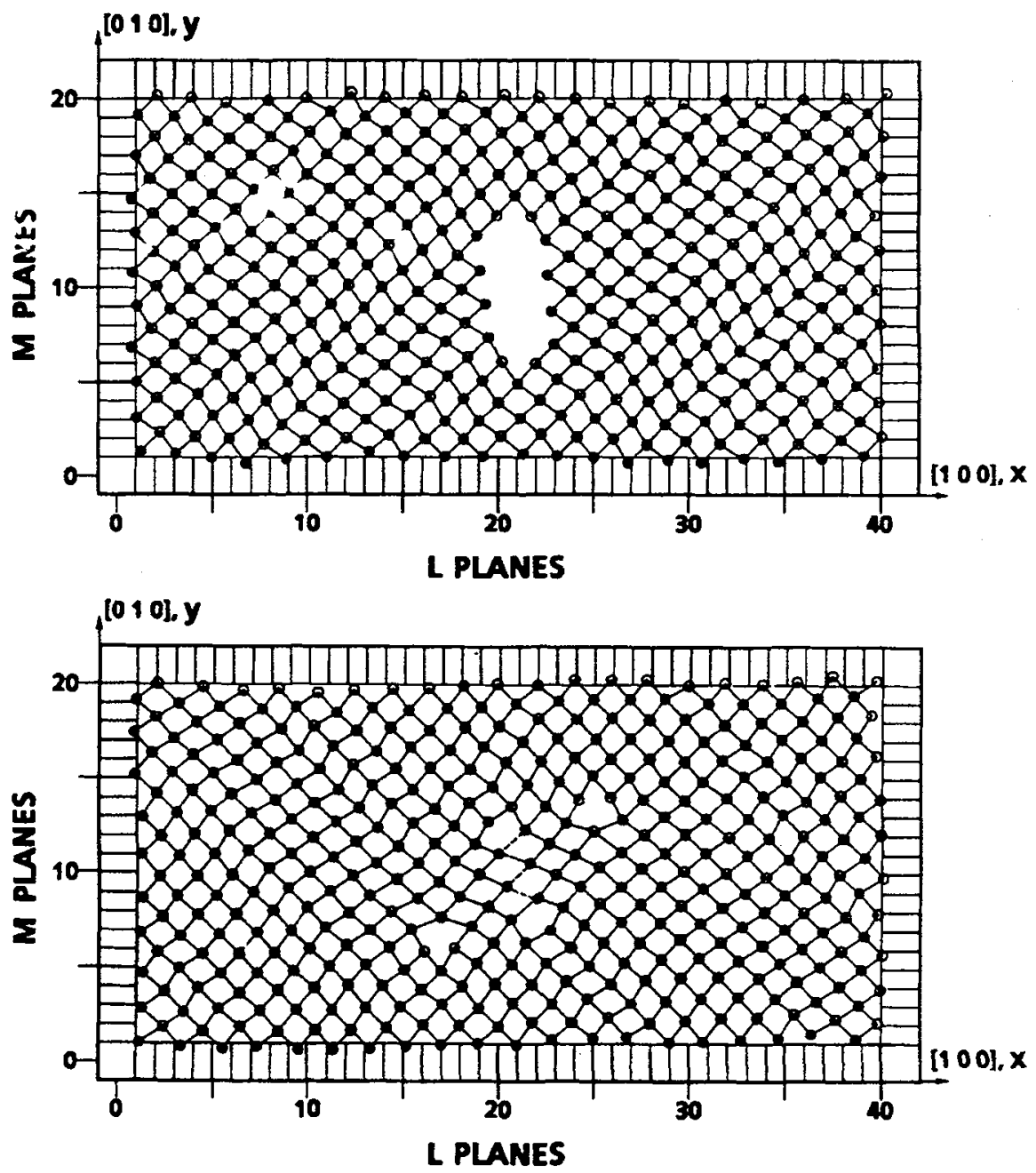

Figure $7 \mathrm{a}, \mathrm{b}$. Vacancy cluster collapsed into dislocation dipoles.

\subsection{Molecular dynamics assessment}

The consideration of events occurring at nanoscale dimensions in shocks has led to a molecular dynamics study of the role that other defects, such as vacancy clusters, may play in generating any proposed dislocation nanostructure [12]. Figure 7 shows a ten atom vacancy cluster in (a) that was found to collapse under imposed shock-type unidirectional displacements to generate a pair of dislocation dipoles in (b). The missing vacancies in (b) are accounted for in the closed planes separating each pair of dislocations constituting the respective dipoles.

An important result that was obtained from monitoring the collapse of the vacancy cluster in Figure 7 and of studying shock influences on other monatomic or molecular vacancy defects [28] was that appreciable hot spot heating always occurred in association with local irreversible plastic relaxation of the structure. Figure 8 shows a representative stress-strain curve for collapse of the vacancy cluster [11]. The method of computing appropriate stresses has been described [29]. Further model calculations of such defect-mediated structural relaxation processes in monatomic and molecular systems have shown that hot spots occur when the potential energy source of the strained lattice is released through an allowed extent of structural relaxation [30]. 

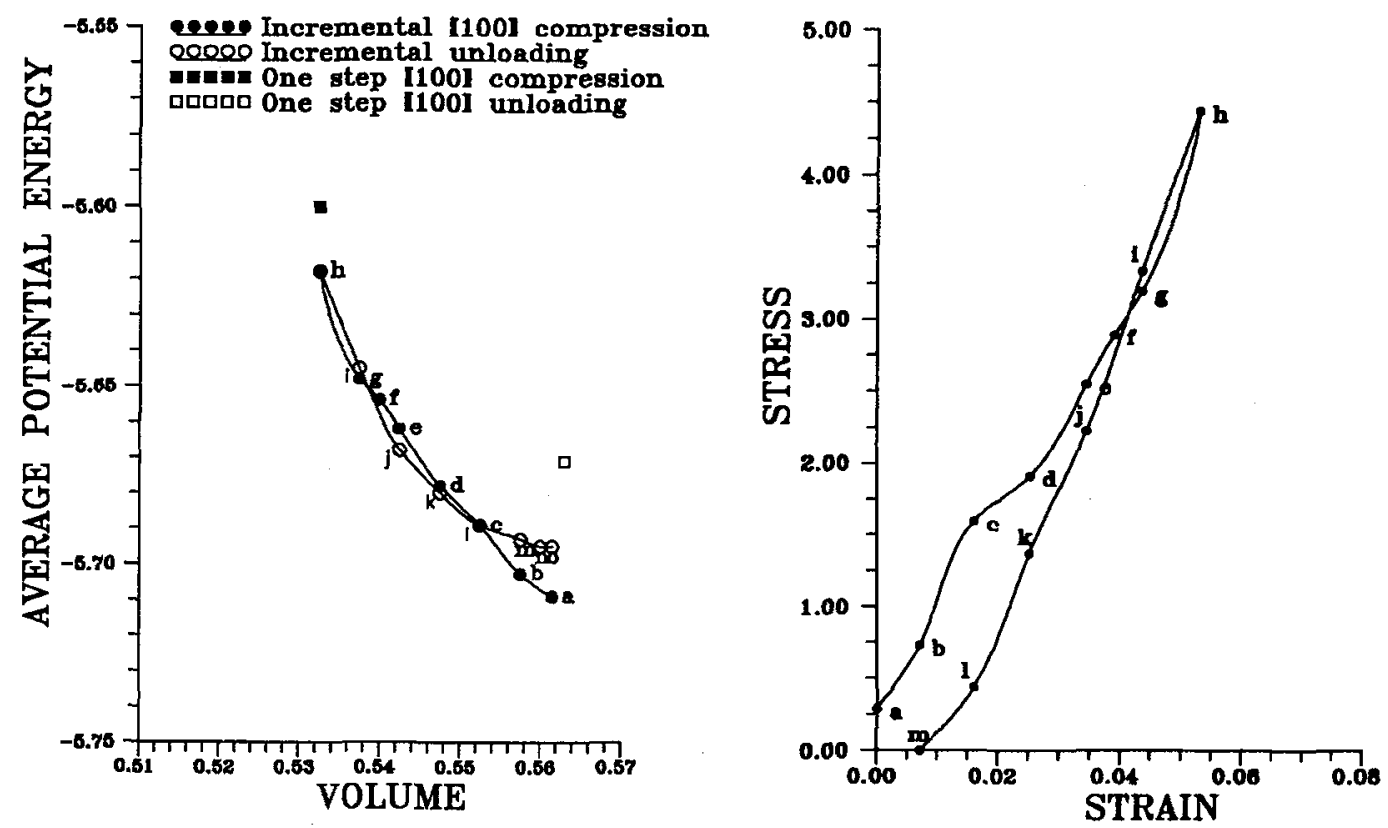

Figure 8. Stress-strain curve for collapse of vacancy cluster.

\subsection{Plastic relaxation mechanisms}

Depending on the strength of the shock, initiation may occur between two limiting cases: at high stress amplitude where pre-existent defects, including dislocation cores, may operate as "in-situ" hot spots of minor requisite thermal excursion [31] or at low stress amplitudes where more substantial plastic relaxation mechanisms are involved for greater localized temperatures. The latter situation is of more interest and relates to the issue of hot spot temperatures that are proposed even for lessor stress amplitude tests, for example, as occur in drop-weight impact tests.

\section{DISLOCATION PILE-UP MECHANICS}

As mentioned earlier, a dislocation pile-up mechanism was proposed to explain the generation of hot spots in drop-weight impact tests [14], as indicated schematically in Figure 9. Here, the dislocation pile-ups in obstructed slip bands could easily span a crystal cross-section or a substantial portion of it. Of course, there is an immediate extent of localization associated with the occurrence of individual slip planes because of their being separated by material that is only elastically strained. However, an obstructed slip band pile-up, if released by collapse of the strongest type of localized obstacle that occurs for the theoretical fracture stress, would produce ultrafast dissipation of the pent-up potential energy for generation of a hot spot.

\subsection{Impact test results}

A proposed susceptibility index for hot spot generation from idealized dislocation pile-up avalanches is displayed graphically in Figure 10 . The limiting temperature relationships for different combinations of material parameters are given in the Figure. The main parameters that vary among the different materials are the theoretical microstructural stress intensity for fracturing, $\mathrm{k}$, and the material thermal conductivity, $K$. The ratio $(\mathrm{k} / \mathrm{K})$ appears to provide a useful susceptibility index that is indicated by the slopes of lines that could be drawn to the various material open circle points in the graph. Otherwise actual values of upper limiting hot spot temperatures are given by the slopes of the lines that are drawn to the closed circle points. Expanded scales for the abscissa and ordinate scales 


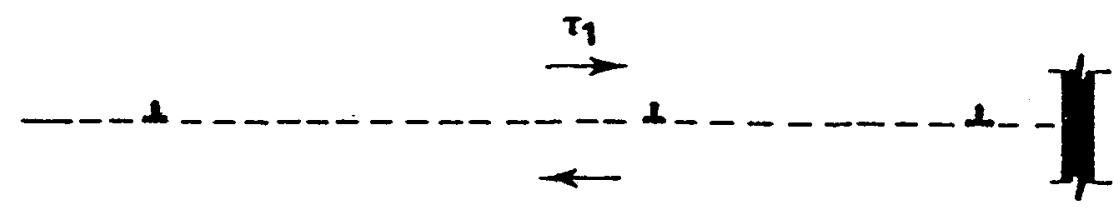

(a) isothermal stress build-up: $\mathbf{n}_{\mathbf{1}}$ dislocations

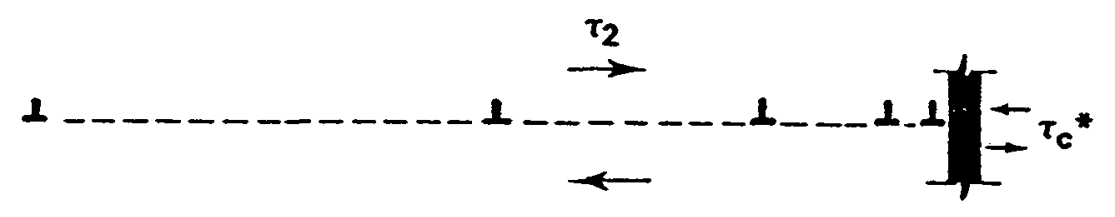

(b) critical stress concentration: $n_{2} \tau_{2}=\tau_{c}{ }^{*}$

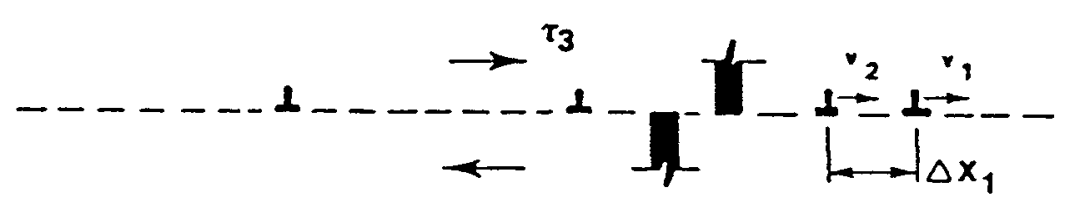

(c) adiabatic collapse-discontinuous load drop

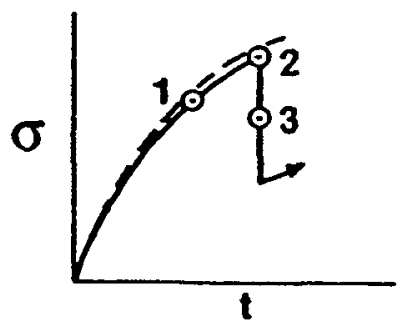

(d) pressure-time curve for $\tau_{1}, \tau_{2}$, and $\tau_{3}$

Figure 9. Dislocation pile-up avalanche model for hot spot.

are shown near to the origin for RDX, PETN and ammonium perchlorate (AP) materials. Such calculations have been carried forward to evaluate the longer hot spot lifetimes that occur for $\mathrm{RDX}$ as compared with PETN and less so for AP [32].

The microstructurally-based pile-up avalanche model description leads naturally to the expectation of a crystal size dependence for the impact drop-height sensitivity. A predicted increase in drop-height initiation with reduction in crystal size was confirmed for RDX [15]. Figure 11 shows a comparison of results obtained for $\mathrm{RDX}$ powder material tested at two laboratories and, also, for tests on octanitrobenzidine (CL-12) material [33]. The vertical spread in Figure 11 of the three RDX dropheight measurements at a crystal size of 250 micrometers is attributed to variations in the microstructures of the specimens that were obtained from different production batches. 


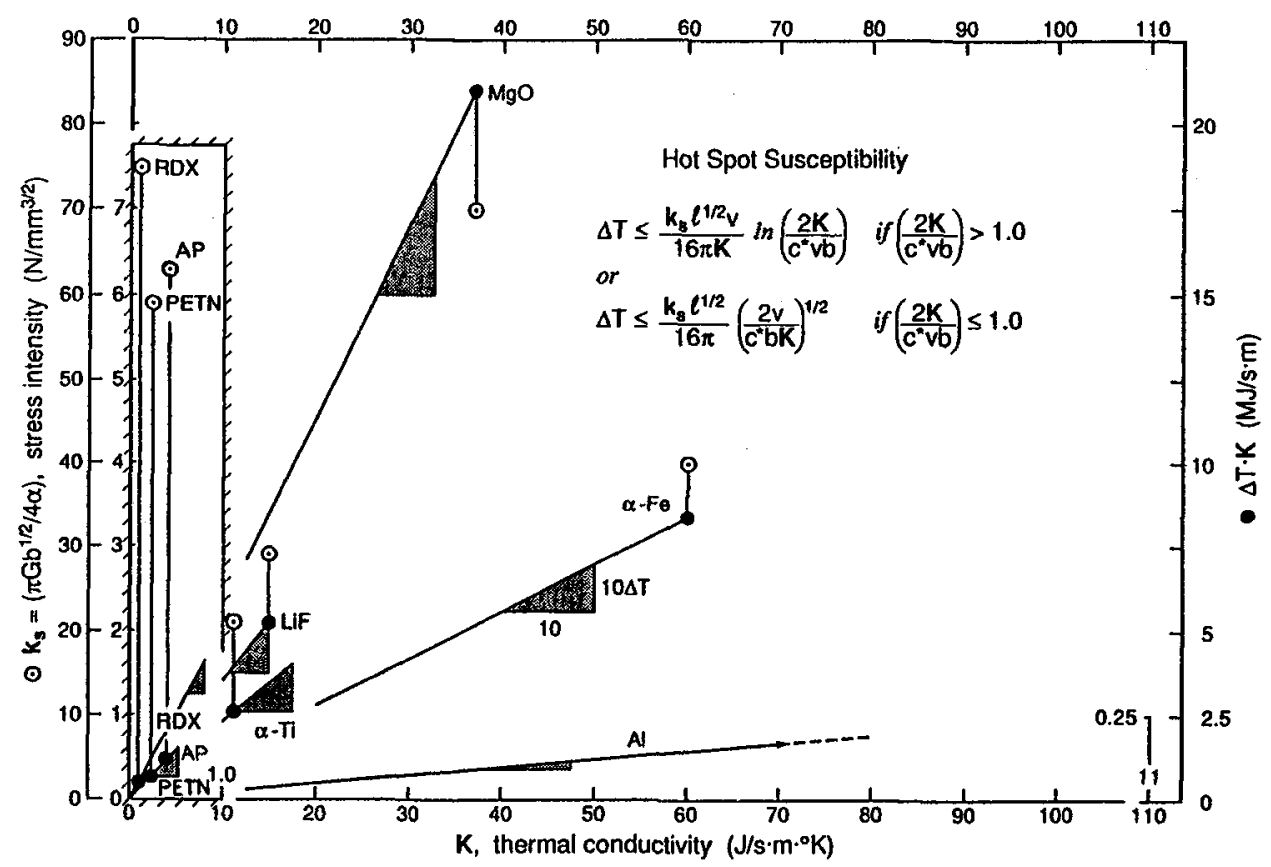

Figure 10. Pile-up based $(\mathrm{k} / \mathrm{K})$ ratio for hot spot susceptibility.

A further consideration of the pile-up avalanche model for mechanical generation of hot spots is its relation to model calculations for thermally-induced hot spots. Figure 12 shows the comparison for RDX and PETN on the basis of one thermal model description [15,34]. An interesting result of the comparison is that PETN should be initiated at lower hot spot temperatures than RDX because of the difference in thermal initiation properties.
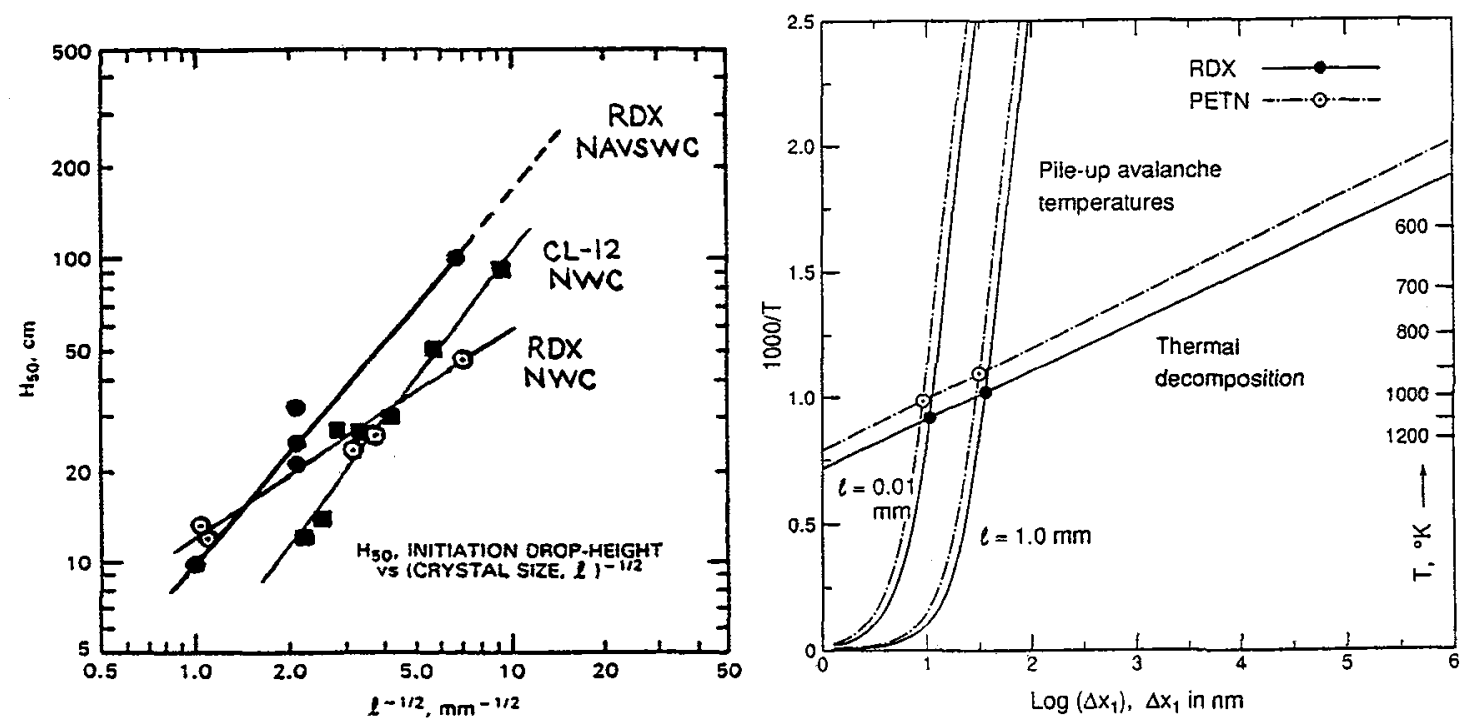

Figure 11. Crystal size dependence for drop-weight sensitivity.

Figure 12. Mechanical and thermal hot spots in RDX and PETN. 


\subsection{Shock connections}

Here, as was mentioned, the interesting case is at low shock amplitudes where the influence of a nanoscale dislocation substructure created in the front is to be encountered immediately by the shockdriven movement of pre-existent slip dislocations. The type of hardening attributed to the nanoscale dislocation network has been measured for shocked AP crystals [35]. In more recent work on AP, shock initiation of chemical decomposition was shown to occur at hardness impressions put into the crystals beforehand [36]. Other work on the occurrence of shear banding in materials bears on the shock hardening issue [37] also in that such hardening is athermal. The strain hardening of the material is unchanged or possibly reduced. Thus, the nanoscale substructure contributes to shear localization or "channeling" of plastic deformation. The result should be an enhancement of hot spot formation. The indication then is that more significant hot spot development would occur for shocked materials than would be expected on the basis of a simple extension of drop-weight impact test results.

\section{CONCLUSIONS}

5.1 The rather unique character of dislocation generation and movement in energetic materials gives an explanation at nanoscale dimensions of how intermolecular distances can be reduced to critical reaction coordinate distances for the direction-dependent shearing of the low symmetry lattice structures.

5.2 In any case, significant hot spot temperatures are always produced by whatever irreversible plastic relaxation mechanisms may occur.

5.3 The detonation of relatively defect-free shocked crystals is very likely initiated just behind the shock front as a result of the pre-existent dislocations interacting with a nanoscale network of dislocation dipoles being sequentially generated at the travelling front.

5.4 For the shock initiation of energetic materials containing microscopic defects, such as surface notches or voids, there is an implicit role of dislocation-based plasticity involved in further localizing hot spot damage.

\section{Acknowledgements}

It is a pleasure to thank Simone Odiot for involving me in this workshop activity and, also, for me to thank colleagues at the Naval Surface Warfare Center (NSWC) for much collaborative work that is reflected in the references cited in this paper and that have shaped my thinking on the topic. Richard Miller is especially thanked for providing support for my work at NSWC and at the University of Maryland, most recently, through Contract N00014-86-K-0286.

\section{References}

[1] Frank F.C., Acta Cryst. 4 (1951) 497-501.

[2] Armstrong R.W., Mater. Sci. Eng. 1 (1966) 251-254.

[3] Armstrong R.W. and Elban W.L., Mater. Sci. Eng. A111 (1989) 35-43.

[4] Armstrong R.W. and Elban W.L., "Microstructural Origin of Hot Spots in RDX Crystals", Energetic Material Fundamentals Workshop, Los Alamos National Laboratory, NM, 14-17 October 1986 (Chemical Propulsion Information Agency Publication 475, 1987) pp. 177-182. 
[5] Elban W.L. and Armstrong R.W., "Microhardness Study of RDX to Assess Localized Deformation and Its Role in Hot Spot Formation", Seventh (International) Symposium on Detonation, U.S. Naval Academy, Annapolis, MD, 16-19 June 1981 (Naval Surface Weapons Center NSWC MP 82-334, 1982) pp. $976-985$.

[6] Dick J.J., Mulford R.N., Spencer W.J., Pettit D.R., Garcia E. and Shaw D.C., J. Appl. Phys. 70 (1991) 3572.

[7] Dick J.J. and Ritchie, J. Appl. Phys. 76 (1994) 2726-2737.

[8] Smith C.S., Trans. Metall. Soc. AIME 212 (1958) 574

[9] Meyers M.A., Scripta Metall. 12 (1978) 21.

[10] Armstrong R.W., Miller R.S. and Sandusky H.W, in "Indentation Hardness, Defect Structure and Shock Model for RDX Explosive Crystals", ONR Workshop on Dynamic Deformation, Fracture and Transient Combustion, Chestertown, MD, 12-14 May 1987 (Chemical Propulsion Information Agency Publication 474, 1987) pp. 77-89.

[11] Bandak F.A., Armstrong R.W. and Douglas A.S., Phys. Rev. B 46 (1992) 3228-3235.

[12] Bandak F.A., Tsai D.H., Armstrong R.W. and Douglas A.S., Phys. Rev. B 47 (1993) 1168111687.

[13] Heavens S.N. and Field J.E., Proc. Roy. Soc. (London) A338 (1974) 77-83.

[14] Armstrong R.W., Coffey C.S. and Elban W.L., Acta metall. 30 (1982) 2111-2116.

[15] Armstrong R.W., Coffey C.S., DeVost V.F. and Elban, W.L., J. Appl. Phys. 68 (1990) 979-984.

[16] Armstrong R.W., "Dynamic/Shock/Dislocation Aspects of Energetic Crystal Decompositions", Shock, Mechanical, and Thermal Initiation-to-Detonation Workshop, Los Alamos National Laboratory, NM, 16-18 November 1993, in print as a Chemical Propulsion Information Agency Publication.

[17] Halfpenny P.J., Roberts K.J. and Sherwood J.N., Philos. Mag. A53 (1986) 531.

[18] Armstrong R.W. and Elban W.L., Mater. Sci. Eng. A111 (1989) 35-43.

[19] Klapper H., Characterization of Crystal Growth Defects, B.K. Tanner and H.K. Bowen Eds. (Plenum Press, NY, 1980) pp. 133-160.

[20] van der Steen A.C. and Duvalois W., "What Do Explosive Particles Look Like", ONR/TNO Workshop on Desensitization of Explosives and Propellants, Prins Maurits Laboratory, Rijswijk, The Netherlands, 11-13 November 1991, Preprints Volume 3, pp.1.

[21] Elban W.L., Hoffsommer J.C. and Armstrong R.W., J. Mater. Sci. 19 (1984) 552-566.

[22] McDermott I.T. and Phakey P.P., J. Appl. Cryst. 4 (1971) 479.

[23] Halfpenny P.J., Roberts K.J. and Sherwood J.N., J. Mater. Sci. 19 (1984) 1629-1637. 
[24] Elban W.L., Armstrong R.W., Yoo K.C., Rosemeier R.G. and Yee R.Y., J. Mater. Sci. 24 (1989) 1273-1280.

[25] Hoffsommer J.C., Glover D.J. and Elban W.L., J. Energetic Mater. 3 (1985) 303.

[26] Armstrong R.W., Ammon H.L., Du Z.Y., Elban W.L. and Zhang X. J., "Energetic Crystal-LatticeDependent Responses", Structure and Properties of Energetic Materials, D.H. Liebenberg, R.W. Armstrong and J.J. Gilman Eds. (Materials Research Society, Pittsburgh, PA 1993) pp. 227-232.

[27] Hammond B.L. and Armstrong R.W., Philos. Mag. Lett. 57 (1988) 41-47.

[28] Tsai D.H. and Armstrong R.W., "Molecular Dynamics Modeling of Hot Spots in Monatomic and Molecular Crystals Under Rapid Compression in Different Crystal Directions", International Conference on Shock Waves in Condensed Matter, St. Petersburg, Russia, 18-22 July 1994, (Russian)

J. Chem. Phys., in print.

[29] Tsai D.H., J. Chem. Phys. 70 (1979) 1375.

[30] Tsai D.H. and Armstrong R.W., "Defect Enhanced Structural Relaxation Mechanism for the Evolution of Hot Spots in Rapidly Compressed Crystals", J. Phys. Chem., in print.

[31] Armstrong R.W. (Traduction: J. Boileau), Revue Scientifique et Technique de la Défense, 16 (1992) 161-164.

[32] Armstrong R.W. and Elban W.L., "Dislocation Roles in Energetic Crystal Responses", ONR/LANL Workshop on the Fundamental Physics and Chemistry of Combustion, Initiation and Detonation of Energetic Materials, Los Alamos National Laboratory, NM, 3-6 March 1992 (Chemical Propulsion Information Agency Publication 589, 1992) pp. 367-378.

[33] Nielson A.T., Working Group Meeting on Sensitivity of Explosives (Center for Energy Technology and Research, New Mexico Institute of Technology, 1987) pp. 256-276.

[34] Boddington T. Ninth Symposium (International) on Combustion (Academic Press, NY, 1963) pp. 287.

[35] Sandusky H.W., Glancy B.C., Carlson D.W., Elban W.L. and Armstrong R.W., J. Propulsion Power (1991) 518-525.

[36] Elban W.L., Sandusky H.W., Beard B.C. and Glancy B.C., J. Propulsion Power 11 (1995) in print.

[37] Armstrong R.W. and Zerilli F.J., Mech. Mater. 17 (1994) 319-327. 